\title{
Polymalformative syndrome with congenital heart defect
}

Síndrome polimalformativa com cardiopatia associada

Sara Pimentel Marcos ${ }^{1}$, Teresa Castro², Anabela Salazar ${ }^{1}$, Rui Anjos ${ }^{3}$

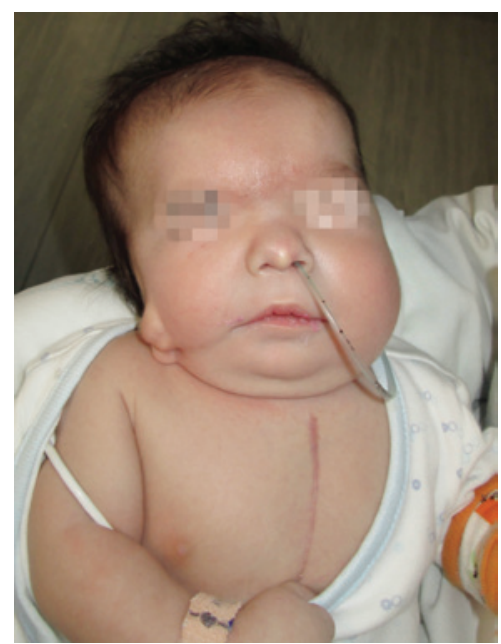

Figure 1. Hypoplasia of right-sided hemifacial, microtia, absence of zigomatic arcade, mandible and maxillary hypoplasia

This is the case of a male newborn whose mother during pregnancy was treated with chloropromazine, topiramate and diazepam, but without any other relevant family history, especially related with congenital malformation. At 34 weeks of gestation, the fetus was diagnosed with transposition of the great arteries (TGA). He born at 37 weeks of gestation, his birth weight was 3,229g and Apgar score 1/7/8. After delivery the he was maintained on invasive ventilation. The postnatal confirmation of TGA was carried out with restrictive foramen ovale throughout Rashkind septostomy done within the 2 hours after birth, under E1 prostaglandin therapy. At 13 days

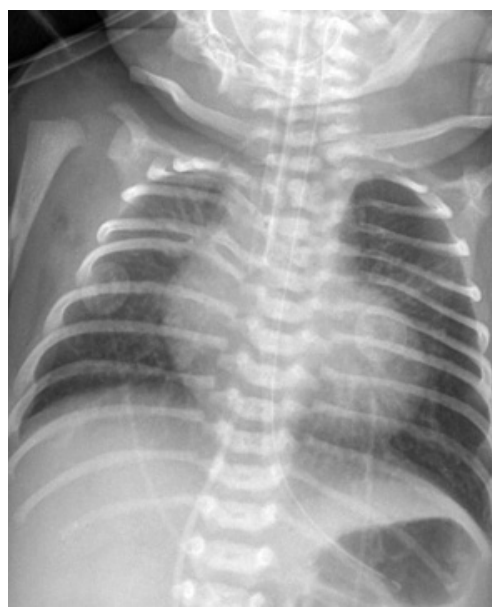

Figure 2. Radiographic image showing cardiomegaly, dorsal hemivertebra, fusions to level of first sixth right arches and apparent malformation of right mandible

after birth, arterial switch operation was performed without significant intercurrences. At birth we observed hypoplasia of right-sided hemifacial, microtia, absence of zigomatic arcade, mandible and maxillary hypoplasia (Figure 1). Ophthalmology assessment highlighted slight ocular asymmetry. The chest radiography showed malformation of dorsal spine with hemivertebrae and fusion of ribs (Figure 2). His renal echography did not reveal malformations. Based on these findings the diagnosis was hemifacial microsomia. We conducted a pluridisciplinary follow-up for surveillance of complications, early intervention and schedule of correction of facial malformation.

\footnotetext{
${ }^{1}$ Hospital de São Francisco Xavier, Centro Hospitalar Lisboa Ocidental, Lisboa, Portugal.

${ }^{2}$ Hospital do Espírito Santo de Évora, Evora, Portugal.

${ }^{3}$ Hospital de Santa Cruz, Centro Hospitalar Lisboa Ocidental, Lisboa, Portugal.

Corresponding author: Sara Pimentel Marcos - Hospital de São Francisco Xavier, Estrada do Forte do Alto do Duque - São Francisco Xavier - Zip code: $1449-005$ - Lisboa, Portugal - Phone: +00351210431441 E-mail: sarasenamarcos@gmail.com

Received on: Aug 5, 2013 - Accepted on: Mar 11, 2014

DOI: 10.1590/S1679-45082015AI2900
} 
The hemifacial microssomia also known as oculoauriculo-vertebral spectrum or Goldenhar syndrome is a result of a change in the development of first and second branchial arches, which is a possible consequence of vascular lesion at an early phase of pregnancy. ${ }^{(1,2)}$ Most of situations are sporadic and family cases are also described in the literature. ${ }^{(3)}$ This syndrome is characterized by combination of auricle malformation and hypoplasia of facial bones. A great phenotypic variability is show and it can be associated to anomalies of the spine, central nervous system, kidneys and heart. ${ }^{(1,2)}$ Heart disease are described in $5-58 \%$ of the patients, being the most frequent the atrial and septal defects or ventricular and ventricular outflow tract. ${ }^{(4)}$ With this case, we emphasize the prenatal diagnosis of a TGA that occurred in a sporadic situation of hemifacial microsomia.

\section{REFERENCES}

1. $\mathrm{OMIM}^{\circledR}$ and Online Mendelian Inheritance in $\operatorname{Man}^{\circledR}$ [Internet]. Baltimore: McKusick-Nathans Institute of Genetic Medicine, Johns Hopkins University School of Medicine; c1966-2013 [cited 2014 Mar 28]. Available: http://www.omim.org

2. Firth HV, Hurst JA. Oxford desk reference: Clinical Genetics. Oxford; Oxford University Press; 2005.

3. Kelberman D, Tyson J, Chandler DC, Mclnerney AM, Slee J, Albert D, et al. Hemifacial microsomia: progress in understanding the genetic basis of a complex malformation syndrome. Hum Genet. 2001;109(6):638-45.

4. Digilio MC, Calzolari F, Capolino R, Toscano A, Sarkozy A, de Zorzi A, et al. Congenital heart defects in patients with oculo-auriculo-vertebral spectrum (Goldenhar syndrome). Am J Med Genet Part A. 2008;146A(14):1815-9. 